\title{
Performance feedback and middle managers' divergent strategic behavior: The roles of social comparisons and organizational identification
}

\author{
Murat Tarakci ${ }^{1}$ (D) । Nüfer Yasin Ateş ${ }^{2,3}$ | Steven W. Floyd ${ }^{4}$ | Yoojung Ahn $^{5}$ | \\ Bill Wooldridge ${ }^{4}$
}

${ }^{1}$ Rotterdam School of Management, Erasmus University, Rotterdam, Netherlands

${ }^{2}$ Faculty of Business Administration, Bilkent University, Ankara, Turkey

${ }^{3}$ Tilburg School of Economics and Management, Tilburg University, Tilburg, Netherlands

${ }^{4}$ Isenberg School of Management, University of Massachusetts Amherst, Amherst, Massachusetts

${ }^{5}$ College of Business, City University of Hong

Kong, Kowloon Tong, Hong Kong

Correspondence

Murat Tarakci, Rotterdam School of Management, Erasmus University, Burgemeester Oudlaan 50, Rotterdam, 3062 PA, The Netherlands.

Email: tarakci@rsm.nl
Research Summary: What drives middle managers to search for new strategic initiatives and champion them to top management? This behavior-labeled divergent strategic behavior-spawns emergent strategies and thereby provides one of the essential ingredients of strategic renewal. We conceptualize divergent strategic behavior as a response to performance feedback. Data from 123 senior middle managers overseeing 21 multi-country organizations (MCOs) of a Fortune 500 firm point to social performance comparisons rather than historical comparisons in driving divergent strategic behavior. Moreover, managers' organizational identification affects whether they attend to organizational- or individual-level feedback. These results contribute to research on performance aspirations and strategy process by providing a multilevel, multidimensional framework of performance aspirations in middle management driven strategic renewal.

Managerial Summary: Middle managers are essential actors in strategic renewal. Their unique positions offer insights into operations alongside knowledge of strategy. In contrast to typical assessments of managerial performance with reference to a prior year, this research shows that performance comparisons relative to peers and other organizational units better motivate managers' divergent strategic behavior. Our results also show that managers who identify with the firm are more attentive to organizational rather than individual performance discrepancies. Thus, our study unveils an important approach for organizations aiming to spark strategic renewal. 


\section{KEYWORDS}

behavioral strategy, middle managers, performance aspirations, strategic renewal, strategic roles, strategy process

\section{1 | INTRODUCTION}

Research on the behavioral theory of the firm (BTF) has shown that managers search for and initiate new ways to improve organizational performance when it falls below aspiration levels (e.g., Baum, Rowley, Shipilov, \& Chuang, 2005; Cyert \& March, 1963; Greve, 1998, 2003a; Harris \& Bromiley, 2007; Kacperczyk, Beckman, \& Moliterno, 2015; for a review see Shinkle, 2012). While this literature has added insight into when and why firms pursue strategic change, it has not unbundled and examined contingencies associated with the type and level of performance feedback that managers attend to. For example, while Cyert and March (1963) have distinguished historical aspiration levels (a firm's recent performance relative to its own past) and social aspiration levels (performance relative to that of other firms), empirical research has tended to aggregate these two reference points (Bromiley \& Harris, 2014; Washburn \& Bromiley, 2012). In addition, past studies have mainly focused on organizational performance feedback. Still, managers receive, and likely heed, feedback about both the organization's and their own individual performances. Finally, while prior research agrees that poor performance produces search, it lacks consensus as to the effects of performance feedback above aspiration levels (e.g., Greve, 2003a; O'Brien \& David, 2014).

To address these research gaps, this study extends the BTF by drawing a broader picture of how different types of aspiration (i.e., historical or social), the direction of the performance discrepancy (i.e., above or below aspirations) and its level (i.e., organizational- or individual-level) all influence managerial behavior. To this aim, we deliberately focus on middle managers. While middle managers run particular units and receive feedback on unit performance, they are also subject to performance systems that regularly provide feedback at the individual level, affecting bonuses and promotions. ${ }^{1}$ Middle managers also lie at the heart of strategic renewal (Floyd \& Lane, 2000; Wooldridge \& Floyd, 1990; Wooldridge, Schmid, \& Floyd, 2008). They bring leadership to the strategy process by searching for new strategic initiatives beyond the boundaries of current strategy that we define here as divergent strategic behavior (Floyd \& Lane, 2000; Floyd \& Wooldridge, 1992). Search in the form of divergent strategic behavior helps organizations overcome inertia and achieve real and lasting strategic change (e.g., Ahearne, Lam, \& Kraus, 2013; Floyd \& Lane, 2000; Wooldridge et al., 2008).

We develop and test hypotheses suggesting that social aspirations are more important drivers of divergent strategic behavior than historical aspirations. This is because performance feedback on social aspirations leaves less room for self-enhancing interpretations justifying poor performance while boosting managerial self-esteem and self-efficacy when performance exceeds social aspirations. We further posit

\footnotetext{
${ }^{1}$ Dual-level performance feedback combined with their role in strategy process differentiates middle managers from top managers and operating managers. Top managers' performance, for instance, is more likely to coincide with the organization's performance, thereby blurring the multilevel distinction we are trying to study. At the lower levels, operating managers are less driven by performance feedback to engage in search activity with strategic implications. We elaborate on the generalizability of our theory regarding top and lower-level managers in the discussion section.
} 
that the strength of managers' identification with the organization shapes their allocation of attention toward different levels of performance feedback. Identification with a higher collective motivates managers to forego personal goals in favor of collective success (Ashforth, Harrison, \& Corley, 2008; Hogg \& Terry, 2000; Mael \& Ashforth, 1992). Thus, we hypothesize that managers who identify strongly with their organizations are more likely to respond to organizational-level feedback than those who identify weakly, and vice versa. Lagged multisource data from 123 middle managers of 21 multicountry organizations (MCOs) of a Fortune 500 company largely support our hypotheses.

Our study offers several significant contributions. First, we present a unique multilevel perspective that integrates the BTF and social identity theory to understand how managers attend to individualand organizational-level feedback. Thereby, we contribute to the attention-based view of the firm (Ocasio, 1997, 2011) and the neo-Carnegie school (Gavetti, Levinthal, \& Ocasio, 2007). The former focuses on how attention affects organizational change, but fails to explain why managers differ in how they allocate their attention. The neo-Carnegie school calls for incorporating recent developments in psychology to enrich the BTF. Recognizing organizational identification as a factor governing managers' attention addresses these calls and represents a new and potentially important contingency in the BTF. Second, we show that feedback on performance discrepancies relative to other units and peers is a potent driver of divergent strategic behavior. This finding adds to the BTF by delineating the type of performance feedback that steers managerial search. Third, while prior strategy process research has unearthed factors that offer resources and skills to carry out strategic activities (for a review, see Wooldridge et al., 2008), factors that unveil why managers engage in divergent strategic behavior in the first place have been overlooked. We therefore advance strategy process research by adding to the understanding of the middle manager behavior that enables strategic renewal.

\section{2 | MIDDLE MANAGERS' DIVERGENT STRATEGIC BEHAVIOR}

In a series of studies, Floyd and Wooldridge (Floyd \& Wooldridge, 1992, 1997; Wooldridge \& Floyd, 1990) describe middle managers' roles in terms of convergent and divergent strategic behavior. Middle managers' convergent strategic behaviors comprise implementing the deliberate organizational strategy by translating it to lower levels and synthesizing new information to top management regarding implementation. Analogous to the notion of search in the BTF, managers' divergent strategic behavior involves facilitating search for new strategic initiatives and choosing which to champion to top management. While convergent strategic behavior in support of deliberate strategy is pre-defined and overtly expected, divergent strategic behavior is most often not formally encouraged by top management (Floyd \& Lane, 2000). That is, divergent strategic behavior is marked by emergent strategies and entails extra-role behavior (Floyd \& Lane, 2000; Nonaka, 1994). ${ }^{2}$ This behavior is vital to the strategic renewal process (Floyd \& Lane, 2000; Pappas \& Wooldridge, 2007) because it populates the intra-organizational ecology with a healthy variety of strategic options (Burgelman, 1994).

Why do middle managers exhibit divergent strategic behavior? Answering this question is essential for a complete theory of strategic renewal. Existing research has investigated much of the individual, organizational and structural factors that enable middle managers' strategic behavior. First, scholars examining the psychological underpinnings of middle manager behavior have found that middle managers' emotional intelligence (e.g., Huy, 1999, 2002) emboldens support for their

${ }^{2}$ Divergent strategic behavior is also distinct from risk-taking. Risk taking entails uncertainty and variability in outcomes (cf. Kacperczyk et al., 2015). However, initiatives that are not anticipated in the organization's deliberate strategy may or may not be associated with outcome variability. 
initiatives. Second, others have studied top management team (TMT) and middle management interactions. Hornsby, Kuratko, and Zahra (2002) have linked managers' strategic behavior with TMT support. Mantere and Vaara (2008) has noted how top management's role expectations spark or hamper middle managers' strategic behavior. Third, organizational structure, low formalization and autonomy (Mom, Van Den Bosch, \& Volberda, 2009), and management control systems (Marginson, 2002) have been identified as creating the setting for initiatives to emerge. Another significant stream of research has associated middle managers' behavior with their positions in the organizational hierarchy (Floyd \& Wooldridge, 1997) and in the social network (Ahearne et al., 2013; Pappas \& Wooldridge, 2007; Rogan \& Mors, 2014). A favorable structural position makes resources and channels available to influence top managers (Dutton \& Ashford, 1993). While existing work has added significantly to our understanding of enablers behind divergent strategic behavior, it fails to explain why managers engage in such behavior in the first place.

We propose performance feedback and social identity as important bases for explanation. Managers search for and champion ways to renew organizational strategy based on organizational-level performance feedback (Cyert \& March, 1963) since they are accountable for their units' performance (Burgelman, 1991; Floyd \& Lane, 2000). Hence, organizational-level performance refers to the unit performance that the middle manager is accountable for. However, individual-performance may also impact divergent strategic behavior because the middle manager's decision to pursue divergent behavior is not "a form of altruism, but ... [is] part of the organization's opportunity structures of career advancement." (Burgelman, 1991, p. 258). Moreover, since social identity defines individuals' goal preferences (Ashforth \& Mael, 1989), we propose that the extent of identification with the organization influences whether managers are drawn to individual- versus organizationallevel performance feedback. Figure 1 depicts our proposed multilevel contingency model for middle managers' divergent strategic behavior, which we describe in the following section.

\section{3 | HYPOTHESES DEVELOPMENT}

\section{1 | Organizational performance feedback as a driver of divergent strategic behavior}

In its classical formulation, the BTF predicts that when organizational performance falls below aspiration levels, such feedback will likely be interpreted to mean that the current strategy has failed to deliver the desired level of performance. While using this formulation as a launch point, we posit two factors shaping the way poor performance feedback is interpreted: (i) a manager's tendency for self-enhancement, and (ii) the competition among units for resources. Building on these two decision frames, one psychological and one organizational, we hypothesize that managers are more likely to heed social rather than historical aspirations when unit performance is below aspirations.

Recent research has noted that response to performance feedback depends on how the feedback is interpreted. In particular, scholars have theorized and found that poor performance triggers a tendency to preserve a positive self-image-i.e., self-enhancement (e.g., Audia \& Brion, 2007; Jordan \& Audia, 2012). Self-enhancement influences how managers identify the cause of low performance and whether they engage in search. For example, objective conditions may indict the organization's strategic posture as the reason for poor performance thus reflecting manager incompetence. Yet, the urge to keep a positive self-image may lead to subjective attributions connected to factors beyond managerial control (Audia \& Brion, 2007).

Poor performance may trigger managers' self-enhancement motive, but the credibility of a selfenhancing interpretation (e.g., "the goal was unrealistic in light of economic conditions") is 


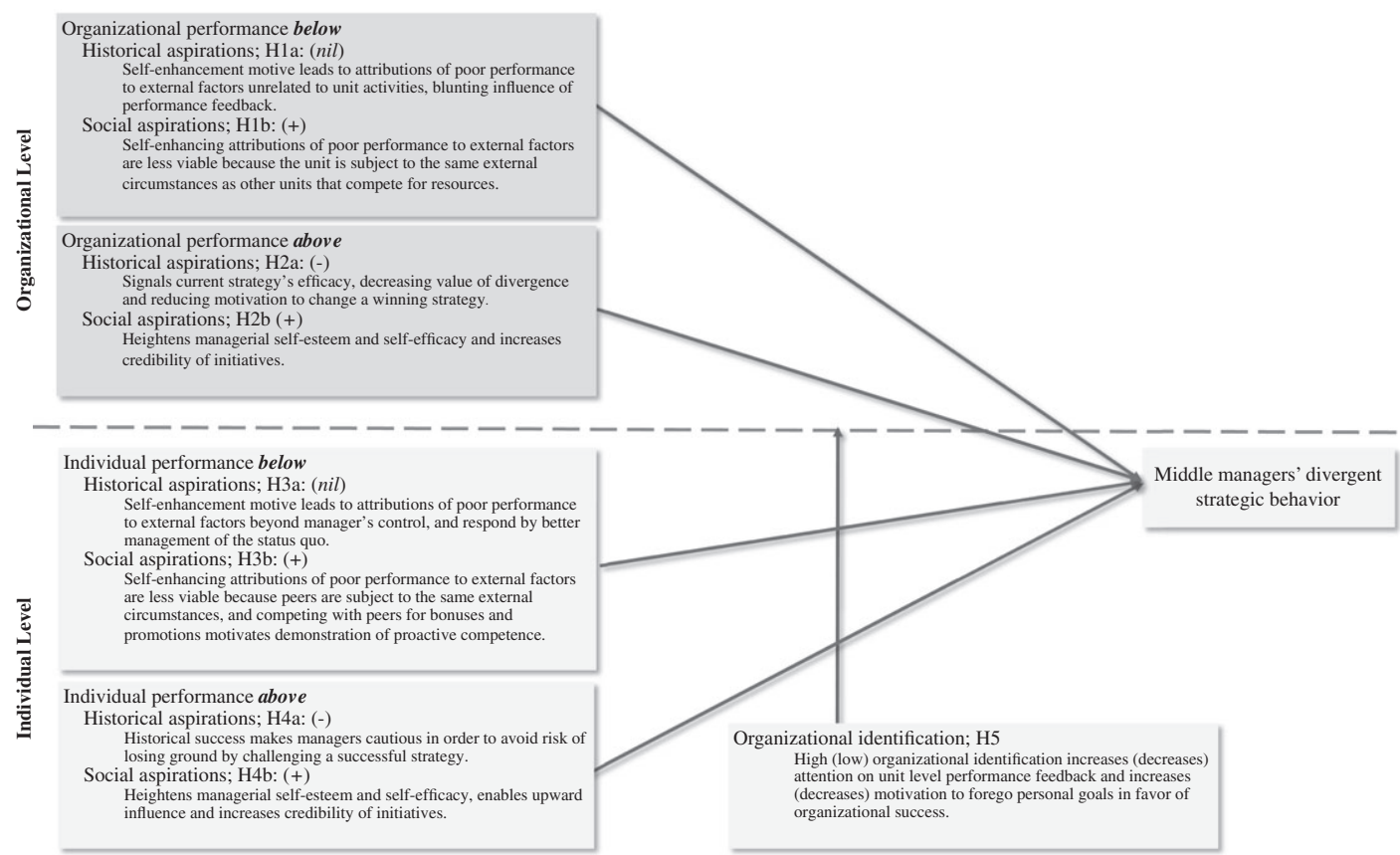

FIGURE 1 Theoretical model

influenced by how the performance gap is defined. When the gap is defined in terms of the unit's historical performance (e.g., aspiring for revenue growth at $10 \%$ over the prior year where the unit achieved only 5\%), managers enjoy leeway in constructing attributions unrelated to unit activities as causes of poor performance. This is because the passage of time incurs some inevitable change in the external environment (e.g., "Bad weather kept shoppers at home;" "A new foreign competitor undercut us on price."). Such interpretations curb the sway of historical aspirations on search, making them less likely to lead to divergent strategic behavior.

However, when the gap is defined in terms of the unit's performance relative to other units in the same business (e.g., aspiring for revenue growth equal to peers where the focal unit achieved significantly lower growth), managers' latitude to construct attributions unrelated to the unit's activities is more constrained. After all, units in the same business are subject to the same goal-setting process from the corporate parent. To foster a sense of fairness and reasonable comparability, firms adjust subunits' goals to reflect strategically relevant differences. Thereby, performance gap comparisons become credible indicators of problems for which middle management can be held accountable. Self-enhancing attributions that rationalize negative performance feedback become less viable. Unit managers are therefore more likely to search for solutions to performance problems by engaging in divergent strategic behavior.

Another situational frame that influences middle managers' response to performance feedback arises from the competitive nature of the resource allocation process among organizational units. While the TMT formulates the overall strategy, especially in multidivisional firms, each unit operates (semi)autonomously and is held accountable for its performance. Units may collaborate and share distribution channels, marketing campaigns and manufacturing for compatible products and services (Hill, Hitt, \& Hoskisson, 1992). Still, resources are allocated to subunits centrally by top management based on differential performance (Gaba \& Joseph, 2013). Put differently, performance comparisons with other organizational units determine resource allocation. Although poor historical 
performance may invoke appeals for additional resources, the intra-organizational resource allocation process typically invests for superior potential returns compared across units (Hoskisson \& Hitt, 1988). Thus, poor performance relative to other organizational units weighs heavily in managers' perceptions about the effectiveness of the unit's current strategy, thereby prompting the decision to search for remedies by pursuing divergent strategic behavior. Consequently, we propose the following hypothesis:

\section{Hypothesis 1 (H1) The lower that organizational performance falls below \\ a. historical aspirations, no effect on divergent strategic behavior will be observed; \\ b. social aspirations, the more divergent strategic behavior will be observed.}

When organizational performance is above aspiration levels, the BTF offers conflicting theoretical and empirical evidence. For example, when performance exceeds aspirations, Greve (2003a) has noted that Japanese shipbuilders decrease R\&D intensity, whereas O'Brien and O'Brien and David (2014) reported an increase for Japanese-owned firms. On the one hand, prior research has argued that when organizational performance exceeds aspirations, inertia pervades (Bromiley, Miller, \& Rau, 2001) - the underlying rationale being that there is no need to alter an already winning strategy. On the other hand, high performance may yield slack resources, and this circumstance creates room for search and experimentation (Baum \& Dahlin, 2007). We resolve these conflicting views via the opposing effects of social and historical aspirations.

When performance is above aspiration levels, we argue that middle managers respond to both their units' historical and social aspirations; but, different interpretations of feedback are in play. On the one hand, when performance exceeds historical aspirations, this feedback signals the strategy's efficacy; and the value of new initiatives that diverge from the strategic status quo is then questioned. Managers' interpretations of positive feedback lead them to perceive divergence from the current strategy as a threat. In addition, a TMT's potential posture of resistance toward altering a winning strategy undermines managers' belief in the success of new proposals, and managers prefer to "stay the course" rather than search.

On the other hand, positive feedback relative to a comparison group (i.e., social aspirations) not only signals a strategy's success, but also reinforces a positive self-image of managers' own skills and organizational capabilities. Their success relative to other units heightens managerial self-esteem and self-efficacy, bolstering the self-enhancing, hubristic tendencies found in many corporate executives (Park, 2007). This heightened self-confidence strengthens middle managers' belief that engaging in divergent strategic behavior will lead to new initiatives that further improve the organization's performance. This prediction is consistent with Tang, Li, and Yang's (2015) finding that hubristic self-confidence influences executives to pay more attention and allocate more resources to innovation. ${ }^{3}$ In addition, a unit whose success stands out relative to other units enjoys greater credibility, making initiatives emanating from the unit more likely to be endorsed by the TMT (Dutton \& Ashford, 1993). Thus, we argue that greater credibility and high levels of selfconfidence arising from outperforming other units frame middle managers' interpretations and offset the BTF's baseline prediction of reduced divergent strategic behavior. Hence, we hypothesize that managers respond to both historical and social aspirations, but these types of feedback work in opposite directions:

\footnotetext{
${ }^{3}$ Although research on executive hubris has thus far centered on top management, its pervasiveness in the general population (Malmendier \& Taylor, 2015) and the fact that senior middle-level executives like those in our sample are likely candidates for future top management positions suggest the relevance of hubris among middle managers.
} 


\begin{abstract}
Hypothesis 2 (H2) When organizational performance exceeds aspirations, middle managers are likely to respond both to social and historical aspirations, such that the more that unit performance increases above

a. historical aspirations, the less divergent strategic behavior will be observed;

b. social aspirations, the more divergent strategic behavior will be observed.
\end{abstract}

\title{
3.2 | Individual performance feedback as a driver of divergent strategic behavior
}

Middle managers aspire not only to advance unit performance; they also seek to improve their individual performance. We argue that divergent strategic behavior emerges when a manager's individual performance is below those of his/her peers rather than when compared to previous-year performance.

Managers want to preserve a positive self-image. Individual performance falling below historical aspirations puts managerial ability in the spotlight. However, they may justify the feedback by attributing the source of poor performance to external circumstances beyond their control (Kluger \& DeNisi, 1996). In such cases, managers see no urgency or need to pursue divergent behavior. Their focus remains on executing deliberate strategy and improving on previously agreed upon objectives, because being a "good soldier" helps fulfill the positive self-image imperative. That is, managers are likely to address historical performance-aspiration gaps by simply doing a better job in implementing status quo objectives and strategy. Thus, it is less likely for negative historical performance discrepancies to spur divergent strategic behavior.

The situational frame of peer-comparisons is also at play when managers perform worse than their peers in the same unit. Here, self-enhancing interpretations become less viable since peers face similar circumstances while attaining more relative success. Confronted with negative peer-to-peer comparisons, managers are likely to feel inferior, resulting in the need to demonstrate proactive competence. Upward comparisons to other more successful peers motivate them to close the performance gap in order to rise into the group of high performers. In this case, divergent strategic behavior becomes a more likely response to the dissonance felt from underperforming one's peers. More objectively, such comparisons imperil bonuses and promotions. This enhances the motivation to develop strategic initiatives that showcase managerial ability and offer superior individual performance outcomes. Accordingly, we propose the following hypothesis:

\section{Hypothesis 3 (H3) The lower that individual performance falls below \\ a. historical aspirations, no effect on divergent strategic behavior will be observed; \\ b. social aspirations, the more divergent strategic behavior will be observed.}

Individual performance that exceeds aspiration levels also stimulates middle managers' divergent strategic behavior. This is because high performance elevates feelings of self-efficacy (Tolli \& Schmidt, 2008) and positive affect (Sitkin \& Pablo, 1992; Wiseman \& Gomez-Mejia, 1998). "[P]eople ... readily undertake activities and pick social environments they judge themselves capable of handling. The higher the perceived self-efficacy, the more challenging the activities they select" (Bandura, 1997, p. 160). Divergent strategic activities are among the most challenging undertakings in organizations since they aim to alter the strategic course of the firm. Krueger and Dickson (1994) likewise noted that individuals who receive positive performance feedback experience higher self-efficacy, viewing new challenges as opportunities despite risks.

The positive boost in self-efficacy is more likely to occur when managers perform better compared to their peers in the same unit than to their own historical performance. There are several 
reasons. Firms' regular conduct of performance appraisals put a manager's promotion or job at stake when peers outperform the manager. This is important because prior research has shown that when such performance pressures are absent, executives may choose complacency and avoid difficult decisions and costly efforts (Bertrand \& Mullainathan, 2003). However, regular performance assessments make middle managers feel the need to perform simply to retain their jobs, bonuses and promotions. Middle managers respected as better performers see value in searching for and championing new initiatives as a way to maintain high-performer status. In addition, their relative performance over peers justifies their proposals in the eyes of the TMT and enables upward influence (Dutton \& Ashford, 1993). This translates to a higher perceived probability of successful execution regarding a worthwhile initiative.

In contrast, positive feedback on historical aspirations suggests that a manager is already on the right track. But, since the reference point is the self rather than peers, there is little basis for feeling superior. Rather than feeling especially confident, managers with historical success actually become more cautious in order to preserve gains already secured. They perceive searching and championing new strategic initiatives as jeopardizing their current high performance. Though these managers, too, are subject to enhanced self-efficacy and positive affect due to the positive historical performanceaspiration discrepancy, questioning the "right track" might be perceived as defiance since it risks losing ground on what already works for the manager. Therefore, successful managers compared to the previous year are likely to engage in less divergent strategic behavior.

\section{Hypothesis 4 (H4) When individual performance exceeds aspirations, middle man- agers are more likely to respond both to social and historical aspirations, such that the higher that individual performance increases above. \\ a. historical aspirations, the less divergent strategic behavior will be observed; \\ b. social aspirations, the more divergent strategic behavior will be observed.}

\subsection{Attending to individual- or organizational-level performance feedback}

Since middle managers typically encounter both individual- and organizational-level feedback, understanding what moves managers to heed one level of feedback over the other is important. Otherwise, research may risk wrongly attributing behavior to one level when another is the actual driver (Kacperczyk et al., 2015).

Toward this end, we draw from the theory of organizational identification- “[an] enduring state that reflects an individual's willingness to define him- or herself as a member of a particular organization" (Haslam, 2001, p. 382). Organizational identification shapes goal preferences in terms of managers' interest in the larger entity (Ashforth \& Mael, 1989). Hence, organizational identification may well explain the relative salience of individual versus organizational performance feedback in driving divergent strategic behavior.

Managers' organizational identification invokes questions about a relational ("who are we?") and a comparative ("how good are we?") sense of identity (Ashforth et al., 2008). Individuals with high organizational identification are more likely to depersonalize themselves (Hogg \& Terry, 2000) and internalize the larger organization's performance and goals as their own (Ashforth et al., 2008; Mael \& Ashforth, 1992). Highly identified individuals further support their organization through their extra-role behavior arising from their emotional attachment to and internalization of organizational norms (Ashforth \& Mael, 1989; Riketta, 2005). Ashford and Barton (2007) also have proposed that more identified people envision collective benefits from their raising of issues, along 
with greater gain for themselves (in seeing themselves aiding a collective that they esteem). Identifying with the organization therefore means that the value of a favorable outcome for the organization is perceived as equivalent to the value of that outcome for the self.

When individual managers lack organizational identification, however, "I" does not become "we" (Brewer, 1991). In this case, individual performance-aspiration discrepancies are more likely than organizational-level ones to trigger divergent strategic behavior. This is because managers are less interested in the success of the organization and may see strategic behavior as a means to advance their own agendas. They lack "the cognitive connection between the definition of an organization and the definition a person applies to him- or herself" (Dutton, Dukerich, \& Harquail, 1994 , p. 242). Self-interest amplifies the perceived benefits of initiatives where the expected outcome contributes to individual performance. Thus, for middle managers with low organizational identification, individual level performance-aspiration discrepancies will be more salient predictors of divergent strategic behavior. Accordingly, we propose:

Hypothesis 5 (H5) When organizational identification is high (low), unit (individual)level performance feedback explains more variance in middle managers' divergent strategic behavior than individual (unit)-level feedback.

\section{4 | DATA AND METHOD}

We collected data from a multinational business unit of a Fortune 500 company operating in the fast-moving consumer goods industry. The business unit comprises a multi-divisional structure: 22 multi-country organizations (MCOs) overseeing all operations in over 70 countries worldwide. An MCO, on average, is composed of 8.86 middle managers (S.D. = 2.32). MCO management teams lead line managers and report to the global TMT of the business unit; the global TMT then answers to the TMT of the company. These MCO managers can therefore be identified as middle managers (Wooldridge et al., 2008).

Since MCOs operate in different markets, they need to make sense of, respond to, and adapt their strategies to their respective markets. Yet, for new strategic initiatives, they must obtain the global TMT's approval and funding. Thus, the middle managers in our sample are well-positioned to search for and champion new strategic alternatives, but they do not have the authority to change the strategy without the TMT's approval.

\section{1 | Data collection}

MCO managers constitute the individual level for our analysis and represent those whose strategic behavior we are interested in examining. To assess managers' strategic activities, we launched an online survey. We targeted all 195 middle managers who managed the 22 MCOs. Eighty-five percent of the respondents completed the survey, providing a sample size of 165. Respondents represented 35 different nationalities with 11.86 years of tenure (S.D. $=7.95$ ) with the organization and 1.95 years of tenure in their current positions (S.D. $=1.24$ ), on average. Sixty-eight percent of the respondents were male, the average age was 40.27 (S.D. $=6.74)$, and $86.6 \%$ had earned a bachelor's degree or higher.

To gauge individual and organizational performance, as well as managers' demographics, we used the firm's HR database. Unfortunately, individual performance data were not available for 42 managers since they had been in the MCO for less than 2 years at the time of our study. This 
caused missing values because we lagged the performance data. Consequently, our final sample size included 123 middle managers and 21 MCOs.

We conducted independent sample t-tests to check if the data included in the analyses significantly differed from the data that we had to discard due to non-response or unavailable performance data. Our tests showed no significant differences between respondents and non-respondents in terms of age, tenure, gender, hierarchical rank, or past performance (where performance data were available) (largest $t$-value was 1.52). Early-late respondent analysis also revealed no significant difference in study variables (largest $t$-value was 1.17). Hence, non-response bias was not an issue. We confirmed that managers with performance data did not differ from managers without performance data in terms of gender or age. However, managers with performance scores had markedly higher tenures (Mean difference $=2.84, t=1.72, p=.09,2$-tailed) and hierarchical ranks (Mean difference $=0.43, t=5.16, p=.00,2$-tailed) as anticipated, since HR disclosed that performance data were absent for newly hired managers. We retained both of these variables as controls.

\section{2 | Measures}

\subsection{1 | Divergent strategic behavior}

Divergent strategic behavior was operationalized as searching for and championing new initiatives. We measured managers' divergent strategic behaviors using nine items adapted from Floyd and Lane (2000) and Floyd and Wooldridge (1997) (Cronbach's alpha =.86). We asked respondents "To what extent do you perform the following activities?" A sample item reads as "Search for new strategic opportunities." The full list of items is presented in Appendix S1.

\subsection{2 | Individual-level performance-aspiration discrepancy}

The organization has a performance management system that annually assesses each manager's individual performance. These assessments are central to the firm and determine managers' bonuses, salary raises, and promotion decisions. This process is managed by the global HR team and is standardized across all MCOs. This makes individual performance scores comparable across MCOs and rules out MCO-level differences in HR policies as an alternative explanation. Individual performance reflected several objective measures and individual development goals. The senior vice president of HR stated that individual performance scores have been normalized by accounting for MCO performance (see Appendix S1). Therefore, individual performance measures are not confounded with MCO performance.

Our theoretical framework has operationalized social and historical aspirations separately. Historical performance-aspiration discrepancy was calculated as the difference between current and prior-year performance. Since our hypotheses argue that responses to performance above and below aspirations differ, we use a spline specification. This splits historical aspirations into two variables allowing slopes to vary for above and below aspirations (e.g., Greve, 2003a, 2008). This specification sets the performance above-historical aspirations variable to zero if current performance is below historical aspirations. Similarly, the performance below-historical aspirations variable is set to zero when current performance exceeds historical aspirations.

To measure social aspirations, we subtracted each manager's performance from the average performance of other colleagues at the same MCO. As with historical aspirations, we calculated separate variables to gauge discrepancy above and below the social aspiration levels. 


\subsection{3 | Organizational-level performance-aspiration discrepancy}

The BTF commonly assumes that firms form their social aspirations by comparing their performance to industry average. Yet, there is ongoing debate that criticizes this practice and recommends that comparison groups be identified according to fit the research context (Kuusela, Keil, \& Maula, 2017). Our field work has revealed that other MCOs rather than external competitors embody the relevant comparison groups (see Appendix S1 for details). This was because, first, the firm had no global competitors active in all MCO markets for comparison purposes. Second, there were no market research firms to provide market data across all MCO markets. Third, as discussed above, the corporate resource allocation process is competitive based on unit performance, making MCOs internal rivals and prompting us to hypothesize other MCOs as the basis for social comparisons.

The company measured MCO performance as a composite score of underlying sales-volume growth and operating margins. While we did not have access to the component values, we were able to obtain final MCO performance scores. We measured each MCO's performance aspirations in the same way as individual aspirations. That is, we considered historical aspirations (i.e., MCO performance in the previous year) and social aspirations (i.e., average performance of all other MCOs), using a spline specification to measure MCO performance above and below historical and social aspirations.

\subsection{4 | Organizational identification}

We adopted five items from Mael and Ashforth (1992) to measure the extent of a manager's organizational identification. A sample item read as "When I talk about [the MCO], I usually say 'we' rather than 'they"' (Cronbach's alpha $=.80)$.

\subsection{5 | Control variables}

Previous research has linked managers' strategic roles with their power (Floyd \& Lane, 2000; Wooldridge et al., 2008) and their network positions (e.g., Ahearne et al., 2013; Pappas \& Wooldridge, 2007; Rogan \& Mors, 2014). To account for these alternative explanations, we controlled for managerial power and network centrality. We used three proxies for managerial power. First, we used hierarchical rank, which is one of the most common measures of power used and recommended in the literature (Tarakci, Greer, \& Groenen, 2016). Second, we calculated a manager's relative tenure as the ratio of the manager's tenure to the others' average tenure in the MCO. Hierarchical rank and relative tenure data were obtained from the HR database. Third, we used the number of connections with TMT members, elicited through a network question asking respondents to name colleagues with whom they most often discussed strategic issues. On average, respondents indicated 5.32 colleagues. Using the same network question, in-degree network centrality was measured as the number of times a manager was mentioned by other colleagues as people with whom they discussed strategic issues. We log-transformed network centrality due to skewness.

MCOs face different local market dynamics. These dynamics may explain the variety of strategic behaviors across MCOs. Therefore, we controlled for market dynamism and competitiveness via three items for each as suggested by Jansen, Van Den Bosch, and Volberda (2006). Sample items read "Changes in my national market are intense" and "Our MCO has relatively strong competitors", respectively. Next, individual responses were aggregated to calculate market dynamism (Cronbach's alpha $=.68$, median $\mathrm{RWG}(\mathrm{j})=0.93$, ICC1 $=0.14$, ICC2 $=0.49$ ) and market competitiveness (Cronbach's alpha $=.87$, median $\mathrm{R}_{\mathrm{WG}(\mathrm{j})}=0.94, \mathrm{ICC} 1=0.09, \mathrm{ICC} 2=0.29$ ).

Finally, politics can affect both the degree of social comparisons and whether or not merit is rewarded (Kreutzer, Walter, \& Cardinal, 2015). We thus controlled for organizational politics using 
the 6-item scale developed by Kacmar and Ferris (1991), with one item omitted due to low factor score. One sample item reads "Favoritism, rather than merit, determines who gets ahead in this MCO team." We aggregated individual responses to quantify perceived politics at the MCO level (Cronbach's alpha $=.77$, median $\mathrm{RWG}(\mathrm{j})=0.91$, ICC1 $=0.20$, ICC2 $=0.64)$. Table 1 presents the descriptive statistics and correlations among variables.

\section{5 | RESULTS}

Middle managers in our data were nested in MCOs, and our theoretical model is built on a multilevel understanding of performance feedback. We tested if managers' strategic behavior indeed varied across MCOs. We estimated a null model without any predictors and examined the MCO-level residual variance of the intercept. The ICC(1) was 0.14 , which indicated that $14 \%$ of the variance in managers' divergent strategic behaviors can be attributed to MCO-level differences. This supports the multilevel nature of managers' strategic behaviors and mandates using a multilevel model that allows random variation across MCOs.

Table 2 presents the results of multilevel regression analyses. Model 1 includes only the individual- and MCO-level control variables. In line with prior research (e.g., Ahearne et al., 2013; Pappas \& Wooldridge, 2007), we found moderate support for more network central managers being more likely to search for and champion new strategic alternatives $(\gamma=0.12$, s.e. $=0.07, p=.07)$. We did not observe a significant effect from managers' hierarchical rank $(\gamma=-0.04$, s.e. $=0.07, p$ $=.59$ ). In addition, we found a positive association between managers' organizational identification and divergent strategic behavior $(\gamma=0.14$, s.e. $=0.06, p=.01)$. The effect of perceived level of politics in an MCO was negative $(\gamma=-0.36$, s.e. $=0.11, p=.001$, Model 4$)$. This finding echoes Kreutzer et al. (2015) who have proposed a negative relationship between politics and the performance of new strategic initiatives.

Hypothesis 1 predicted that the lower an MCO's performance falls below the performance of other MCO's, the more the divergent strategic behavior, but not when an MCO's performance falls below its performance in the previous year. Models 2-4 test this hypothesis. First, we observed that one standard deviation drop of MCO performance below social aspirations increased managers' divergent strategic behavior by 0.35 standard deviations $(\gamma=-0.35$, s.e. $=0.11, p=.002$, Model 4). Recall that a negative coefficient in the spline specification below aspiration levels is associated with increased values of the dependent variable. However, we did not observe a significant relationship when MCO performance fell below historical aspirations $(\gamma=0.08$, s.e. $=0.07, p=.28)$. Second, we conducted a $t$-test with the null hypothesis that the coefficient of social aspiration is larger than that of the historical. This t-test provided empirical support for social aspirations being more salient $(t$-score $=2.96, p=.002,1$-tailed) than historical ones. These results support Hypothesis 1 .

Hypothesis 2 proposed that, in the case of positive organizational performance-aspiration discrepancy, both social and historical organizational-level aspirations will drive strategic behavior, but in opposite directions. Model 4 shows that divergent strategic behavior decreased by 0.3 standard deviations as MCO performance exceeded MCO historical aspirations by one standard deviation $(\gamma$ $=-0.30$, s.e. $=0.09, p=.002$ ) ; whereas, divergent behavior increased when MCO performance increased beyond the other MCO's average performance $(\gamma=0.28$, s.e. $=0.09, p=.003)$. These results support Hypothesis 2.

Hypothesis 3 focused on individual-level aspirations to propose that divergent behavior increases when individual performance falls below social but not historical aspirations. Models 5-7 test this hypothesis. We found that managers carry out divergent strategic behavior when the discrepancy 


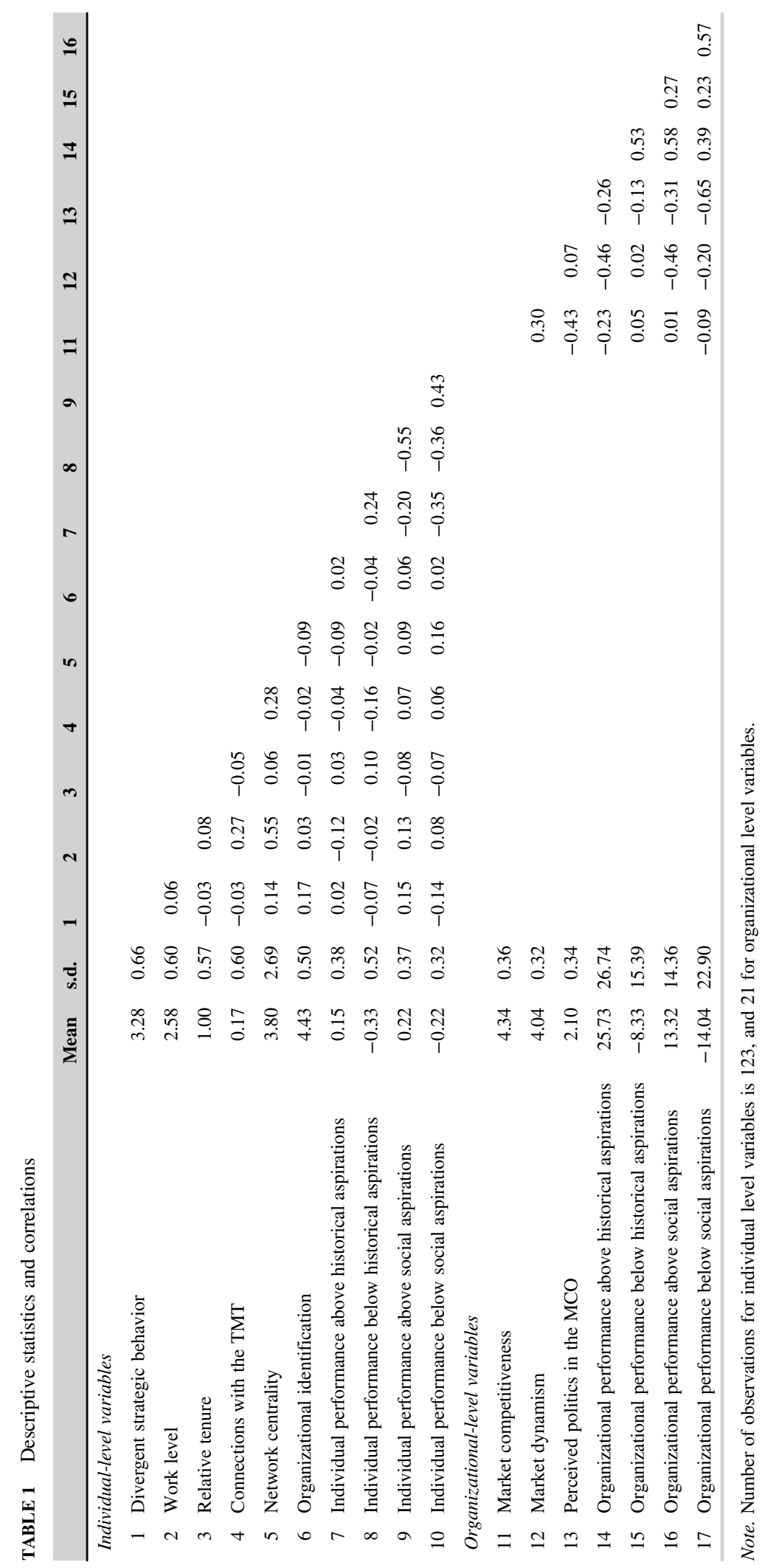




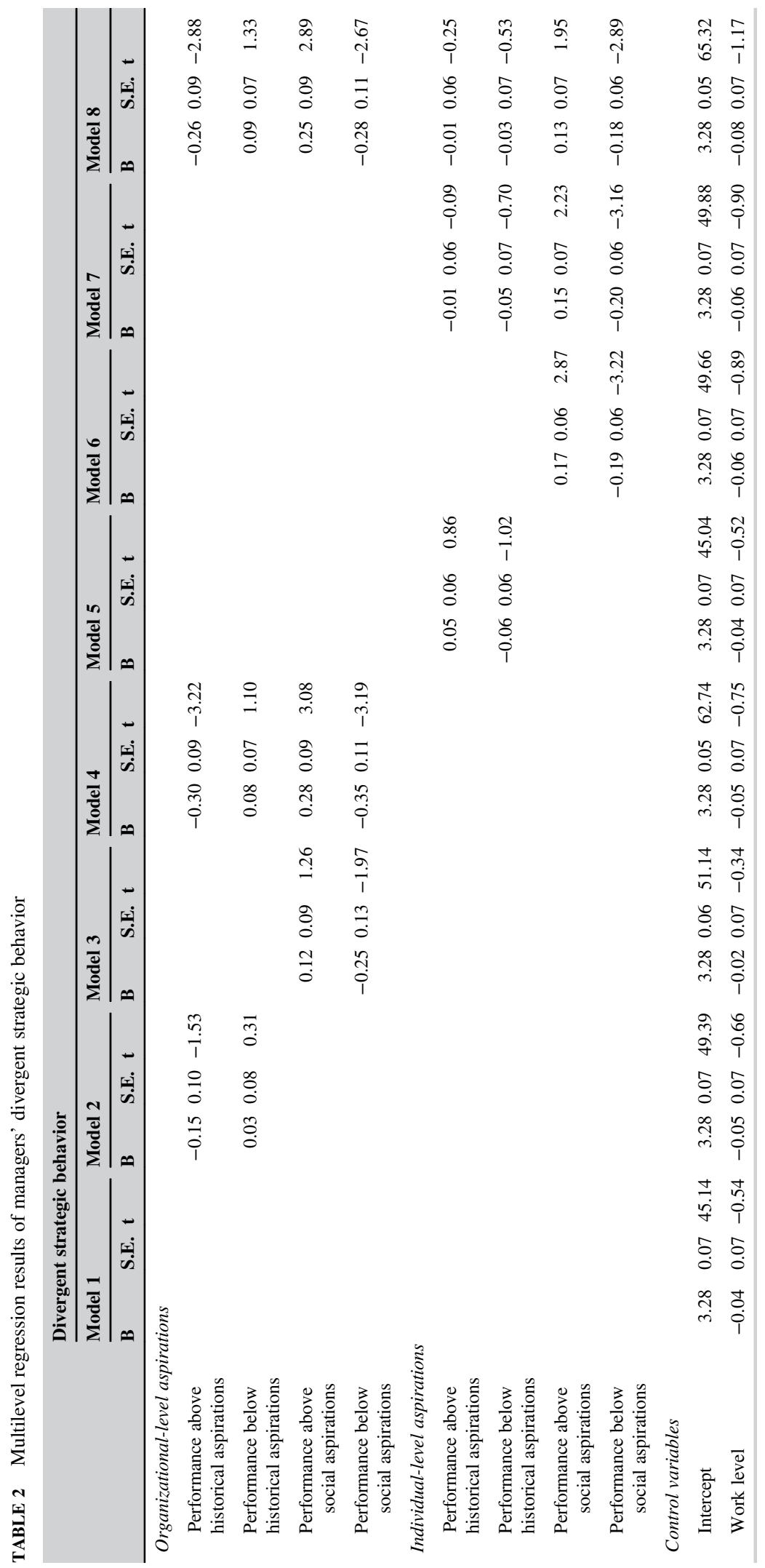




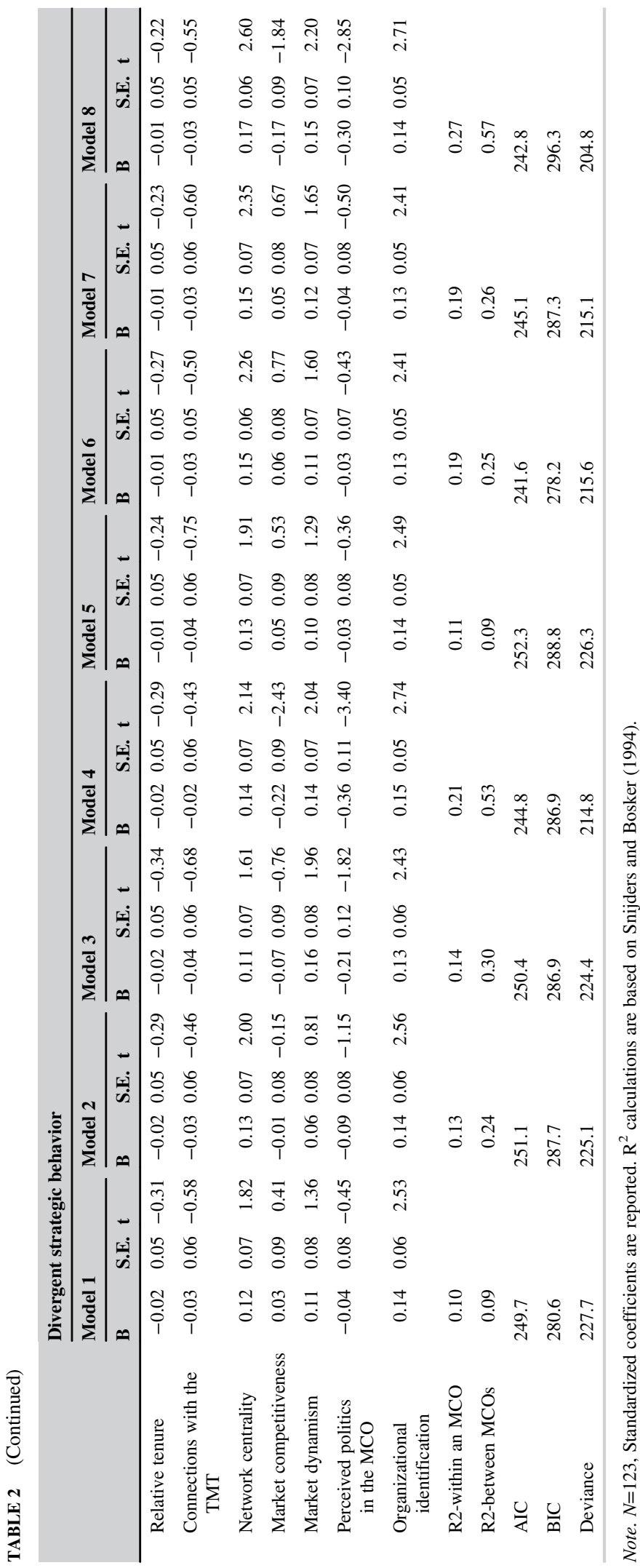


between their individual performance and that of peers widens $(\gamma=-0.20$, s.e. $=0.06, p=.002$, Model 7). However, this was not true for individual performance below historical aspirations $(\gamma=$ -0.05 , s.e. $=0.07, p=.48$, Model 7). Conducting a $t$-test on Model 7 coefficients demonstrated that the effect size of social aspirations is significantly higher than that from historical aspirations ( $\mathrm{t}-$ score $=3.26, p=.001,1$ - tailed). Thus, Hypothesis 3 is supported.

Hypothesis 4 predicted that when individual performance is above aspirations, social and historical aspirations drive divergent strategic behavior in opposite directions. Models 5-7 results offer partial support for this hypothesis. Specifically, we observed that a positive discrepancy between individual performance and social aspirations does promote divergent strategic behavior $(\gamma=0.15$, s.e. $=0.07, p=.028$, Model 7). In contrast, although the sign of the coefficient for historical aspirations is in the predicted negative direction, the effect was not statistically significant $(\gamma=-0.01, \mathrm{~s}$. e. $=0.06, p=.93$, Model 7). These results agree with the hypothesis that middle managers' divergent behavior spawns from positive discrepancies in individual level social aspirations, but do not support the hypothesized negative influence of positive historical discrepancies at the individual level.

Hypothesis 5 proposed that the extent by which individual- versus organizational-level discrepancies drive divergent strategic behavior is contingent on a manager's degree of organizational identification. We conducted a median split sample analysis ${ }^{4}{ }^{5}$ Results appear in Table 3. Models 1-3 show that for managers with low organizational identification, only individual-level social aspirations are salient enough to spark divergent strategic behavior when managers underperform their peers. Using log-likelihood tests, we compared the variance explained in each model in the last row of Table 3. Comparing Model 1 and Model 3, we found that inserting individual-level performance feedback in Model 1 explained significant additional variance $\left(\chi^{2}(4)=8.98, p=.062\right.$, Model 1 vs $3)$. In contrast, adding organizational feedback to Model 2 did not increase explanatory power $\left(\chi^{2}\right.$ (4) $=2.20, p=.698$, Model 2 vs 3). Models 4 and 5 present results for managers with high organizational identification. For these managers, adding organizational-level performance feedback significantly increased the variance accounted for $\left(\chi^{2}(4)=13.04, p=.011\right.$, Model 5 vs 6) while individual-level feedback failed to account for additional variance $\left(\chi^{2}(4)=5.80, p=.214\right.$, Model 4 vs 6). Hence, we conclude that for managers with low (high) organizational identification, individual- (organizational-) level performance feedback explained significant variance in their divergent strategic behavior. These results provide support for Hypothesis 5.

We collected qualitative data to better understand the context rather than for the purpose of confirming our results. Still, anecdotal evidence from interviews of middle managers is consistent with the quantitative findings. The Appendix S1 provides excerpts from our interviews with two middle managers working in the same MCO. The interviewed managers' MCO performed below other MCOs. One manager performed above and while the other below their peers, yet they both championed strategic

\footnotetext{
${ }^{4}$ Split sample analyses are often criticized for reducing the statistical power (Aguinis, 1995; Maxwell and Delaney, 1993). However, in multilevel analyses, the statistical power is also determined by the number of observations at the second level (Gelman and Hill, 2006). Therefore, median-split at the individual-level does not reduce statistical power since the number of observations at the second level remains unchanged.

${ }^{5}$ An alternative way of testing the moderating effect of organizational identification was to create multiplicative interaction terms. However, this would have required introducing eight more variables: type (i.e., social, historical) $\times$ direction (above, below) $\times$ level (i.e., individual, organizational) combinations. Additional variables reduce degrees of freedom as well as statistical power. Overcoming this limitation to some extent, another alternative was to aggregate the historical and social aspirations into individual- and organizational-level by taking a weighted average of them. Finding correct weights is a challenge. Scholars often try all the alternative combinations of weights (e.g., Greve, 2003a, see also Bromiley \& Harris, 2014 and Washburn \& Bromiley, 2012 for reviews). However, not only did we theorize conflicting directions for historical and social aspirations, but such an aggregation has been criticized for lacking a theoretical basis (Bromiley \& Harris, 2014; Washburn \& Bromiley, 2012).
} 


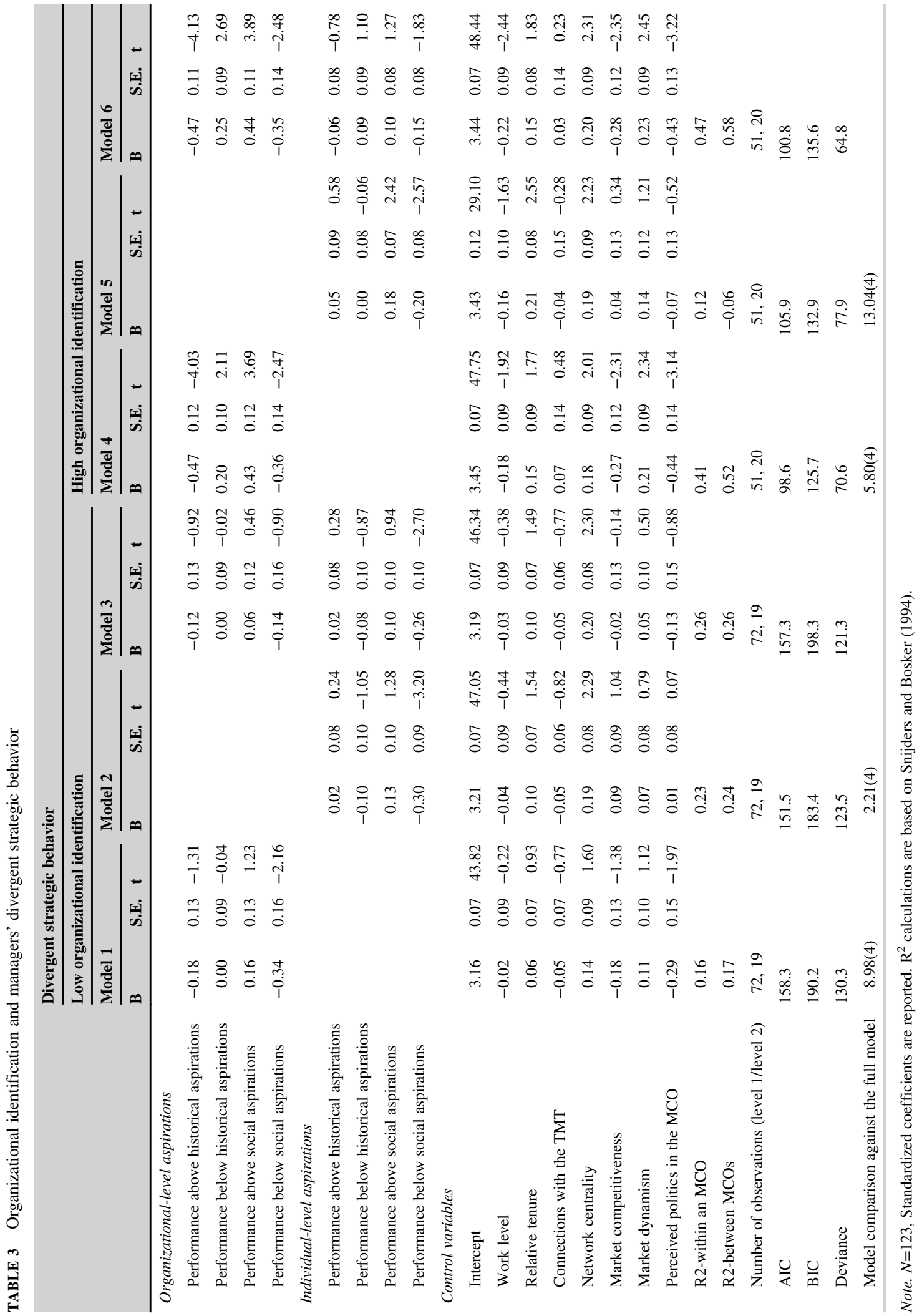


initiatives — one focusing on sustainability, the other on staffing a new kind of sales team. The observation of divergent strategic behavior in both managers is consistent with the results for Hypotheses 3 and 4. We also note differences in the managers' level of organizational identification and the corresponding content of their chosen initiative. The manager with lower identification chose to champion the narrower, functionally-oriented sales team staffing initiative that was more likely to be responding to individual performance feedback. The manager with high organization identification, though, advocated the broader, cross-functional sustainability initiative that was more likely to influence unit-level performance.

\section{1 | Alternative explanations}

We focused on social-historical performance comparisons at individual-organization levels and their effects on divergent strategic behavior in an attempt to explain drivers behind this extra-role behavior. In this subsection, we consider two possible sets of alternative explanations: one based on the institutional and cultural contexts of the MCOs, and a second based on organizational structure and resource interdependencies among the MCOs.

\subsection{1 | MCOs' home country institutions and culture}

Greve (2003b, p. 697) has argued that "cultural and institutional differences may cause differences in responsiveness to different goal variables." Because MCOs in our sample span multiple cultures and institutional contexts, these differences may have been an important force impeding or encouraging divergent behavior by regulating the acceptance of extra-role behaviors and/or the importance that managers attach to aspirations. We examine four factors that have cultural and institutional implications.

Regarding the cultural factors, we controlled for Hofstede's collectivism and uncertainty avoidance cultural dimensions (Hofstede, Hofstede, \& Minkov, 2010). Collectivist cultures are prone to espouse compliant behavior where straying from the norm-e.g., the deliberate strategy—is rare and perceived negatively. Likewise, uncertainty avoidance entails whether the culture is intolerant of behavior that may inject uncertainty arising from divergent strategic behavior. We obtained the relevant indices from Hofstede's webpage. ${ }^{6}$

Considering institutional factors, we added degree of business freedom and political constraint as controls since managers may attribute poor performance to institutional context in countries with political turbulence, and these obstacles to doing business may hinder managers from search. To measure business freedom, we used the Index of Economic Freedom, which is computed by the Heritage Foundation (2017). To measure political constraint, we used Henisz's (2000) Political Constraint Index (POLCON V).

None of these added controls had statistically significant coefficients (largest $t$-value belonged to uncertainty avoidance; $\gamma=-0.13$, s.e. $=0.08, t=-1.67$ ). Nor did they explain any significant variance $\left(\chi^{2}(4)=3.43, p=.49\right)$. The effects of performance feedback remained qualitatively similar. Only when we included both cultural and institutional controls, the effect of organizational performance above historical aspirations became significant at $p=.10$ level $(\gamma=-0.17$, s.e. $=0.10, p=.08,2$ tailed $)$, in line with Hypothesis 2a. We thus concluded that performance feedback explains managers' divergent strategic behavior above and beyond cultural and institutional contexts.

\subsection{2 | Organizational structure and resource interdependencies}

We acknowledge the potential role of organizational structure as a setting for intra- and interorganizational behavior. For the firm in our study, for example, one could argue that our hypotheses

${ }^{6}$ https://geert-hofstede.com/national-culture.html. 
might have panned out differently had the organizational structure fostered inter-unit cooperation (e.g., vertical integration, shared services and other "synergies"). At the same time, such structures ease the development of close and frequent interactions across units, which could logically be associated with a greater tendency to rely on social comparisons (Obloj \& Zenger, 2017)—creating a context that would favor our hypotheses. The units in this study were not organized this way: MCOs were dispersed across heterogeneous geographic regions, thereby limiting interdependency among MCOs. They did not share marketing, sales or manufacturing facilities. Instead, global functional teams running support functions such as Human Resources, Finance and Information Technology facilitated coordination across MCOs. Divisions operated independently from one another, a pattern typical of unrelated structures (Hill et al., 1992) having few opportunities to form close and frequent interactions. The fact that social comparisons were important even in this setting suggested that structure, at least in this form, likely did not account for our findings.

\section{6 | DISCUSSION}

Middle managers, positioned in between operational realities and organizational strategy, are at the forefront of the strategic renewal process as they search for and champion new strategic initiatives. To better understand the factors influencing why and when middle managers engage in divergent strategic behavior, we developed a multilevel model of performance aspirations and tested it using a sample of middle managers at a business unit of a Fortune 500 company. We found that managers' individual- and organizational-level social aspirations influenced their divergent strategic behavior. In addition, our results earmarked organizational identification as a key factor influencing the relative salience of organizational and individual level aspirations. These findings offer important contributions to research within the BTF tradition (i.e., performance aspirations, the neo-Carnegie school, and the attention-based view) and to strategy process research.

\section{1 | Theoretical implications}

\subsection{1 | The BTF tradition}

We advance the BTF by explaining how managers' aspirations are formed and attention is allocated. Prior research on performance aspirations has established strategic renewal as a response to performance feedback, but it has mainly focused on firm-level performance and behavior. However, strategic initiatives that fuel renewal also emanate from middle and lower levels. These managers often recognize the need for strategic change sooner than senior executives and engage in emergent adaptive behaviors as a response (Burgelman, 1991; Floyd \& Lane, 2000; Wooldridge et al., 2008). By expanding the scope of managers beyond top management, we thereby extend the relevance and applicability of the BTF to understand individual managers' strategic behavior. Furthermore, prior research has cast search as a broad construct involving exploration and exploitation, with much empirical investigation spanning R\&D investment, capital investment, and mergers and acquisitions. We add divergent strategic behavior as another relevant type of search, an especially appropriate type in the middle management context. That is, managers' divergent strategic behavior not only involves facilitating the search for new strategic initiatives, but also entails choosing which ones to champion to top management.

Equally important, lower, middle and top managers alike receive feedback not only at a collective (e.g., firm, unit, team) level, but also at the individual level. Organizational performance feedback might seem too distant for lower level managers; yet, they are still held responsible for the performance of their 
teams. Hence, feedback on team performance, as well as individual performance, should be relevant for lower level managers. Regarding top managers, the BTF explains their strategic behavior by assuming that organizational and individual performance are aligned through instruments such as stock options in the executives' compensation plans (Wiseman \& Gomez-Mejia, 1998). If this alignment is weakened, top managers are deemed likely to divide their attention between individual and organizational performances. Our study not only proposes a richer, multilevel understanding of performance feedback, but also helps to explain when managers attend to individual- versus organizational-level feedback.

We herein respond to appeals from the neo-Carnegie school to incorporate recent insights from psychology as a complement to the BTF (Gavetti et al., 2007). Toward this end, we make a potential contribution to the field's understanding about when middle managers' divergent strategic behavior contributes to firm renewal versus when it reflects self-serving individual goals. Our findings show that managers with high organizational identification seek to close gaps between their organization's performance and those of other organizations. Managers with low organizational identification, however, are more attuned to the gap between their own individual performance and the performance of social referents. Because social identity constitutes an important part of the self-concept at all levels of the hierarchy (Mael \& Ashforth, 1992), these findings can be extended from the middle to both lower level and top managers. Broadly, our results thus suggest a contingent association between managerial behavior and performance feedback. This insight is important because the uncertainty surrounding divergent strategic behavior makes it difficult to specify and incite in advance with formal incentives (Floyd \& Lane, 2000). Even long-run incentives such as stock options for top executives may not encourage attention to organizational performance discrepancies and search associated with divergent strategic behavior (Sanders \& Hambrick, 2007).

Relatedly, we further add two novel insights to the attention-based view, which argues that managers selectively attend to a limited of set of stimuli (Ocasio, 1997, 2011). First, in support of this view, we found that both organizational- and individual-level social aspirations underpin managers' strategic behavior. This finding demonstrates that attention allocation encompasses type, direction, and level of performance feedback. The opposing effects of social and historical aspirations when performance exceeds aspirations is one example of how the type of feedback influences attention, shedding light on various conflicting findings in prior research (e.g., Baum \& Dahlin, 2007; Bromiley et al., 2001; Greve, 2003a; O'Brien \& David, 2014). Another example is the relative salience of social over historical aspirations. When aggregating historical and social aspirations into a single aspiration level through grid search, prior research has assumed more weight for social (e.g., Greve, 1998, 2003a, 2008) or historical aspirations (e.g., Gaba \& Joseph, 2013). We propose a finer-grained understanding of how managers differentially allocate their attention to both social and historical aspirations at multiple levels.

Second, Ocasio (1997, p. 189) has argued that "cognition and action of individuals are not predictable from the knowledge of individual characteristics, but are derived from the specific organizational context and situations that individual decision-makers find themselves in." Perhaps, this is why the attention-based view has argued that "decision-makers are more likely to consider and to attend [issues] with greater legitimacy, value, and relevance to the organization" (Ocasio, 1997: 198). In stark contrast, our study demonstrates that managers' individual traits (e.g. their organizational identification) do matter, and this might be why managers may not always attend to what is more relevant and valuable for the organization. We found that those managers may not allocate attention to feedback related to their organizations' performance because of their low organizational identification. We thus advise the incorporation of individual characteristics to help explain managerial attention and self-serving behavior. 


\subsection{2 | Strategy process}

An important contribution here is to strategy-process research, and particularly to the study of middle managers' strategic behavior. Prior research has offered unique insights by associating middle managers' strategic behavior with certain hierarchical ranks (e.g., Dutton \& Ashford, 1993; Floyd \& Lane, 2000; Wooldridge et al., 2008) or network positions (e.g., Ahearne et al., 2013; Pappas \& Wooldridge, 2007; Rogan \& Mors, 2014). In contrast, our findings showed that behavioral factors beyond rank or connection (i.e., discrepancy between performance and aspirations) can offer fresh ways of fathoming managers' strategic behavior.

The behavioral perspective that we take at the individual level adds to the literature on middle managers' psychological traits and identities that impact strategy (e.g., Huy, 1999, 2002; Vuori \& Huy, 2016). The behavioral approach also allows for a more nuanced understanding of middle manager behavior in the strategy-making process by spotlighting performance feedback as a driver of divergent actions. Our contribution leads to a better explication of the intricacies embodying the important role that middle managers play in strategic renewal.

The potential reliance on organizational identification and the fact that it varies widely among managers (Glynn, 2000) provides another reason why renewal poses a difficult challenge for organizations. This offers support for the proposition that notable variations in organizational identification among key managers may imperil organizational performance (Voss, Cable, \& Voss, 2006). Strategy process research that investigates the relationship between managers' behavior, the renewal process and firm performance may be well served by a focus on the social identity perspective.

\section{2 | Limitations and future research}

We studied several MCOs within the same Fortune 500 firm. This focus comprised comparable organizations and allowed us to control for unobserved firm-level heterogeneity (e.g., organizational culture, incentive schemes, organizational structure, etc.); however, this choice limits the empirical generalizability of our findings.

First, our qualitative interviews revealed that the firm made regular performance comparisons among MCOs instead of comparisons against the competitors due to lack of global competitors and reliable market data (see the Appendix S1). Accordingly, these internal comparisons were more salient for MCO managers in our context. Yet, we acknowledge that defining social aspirations relative to competitors might also be relevant in different contexts.

Second, although our data contain a representative sample of all MCO managers within the focal business unit, our sample size is rather small. This makes it harder to detect true effects hidden by low statistical power. This might be why we did not observe a significant effect for variables such as historical aspirations and hierarchical rank. However, more observations or new samples may yield effect sizes of different magnitudes. We encourage future research to replicate and advance our findings with larger samples to confirm or refine our results.

Third, we acknowledge the potential role of organizational structure in setting intra- and interorganizational contexts, which could be an important force impeding or encouraging divergent behavior. Our setting was not appropriate to examine this effect since our data came from different organizations (MCOs) of a business unit using the same organizational structure and HR practices. Although this controlled for structure effects to make comparisons across the MCOs more reliable, structural differences among units remains a fruitful research path. 


\section{3 | Conclusion}

This study explained how individual- and organizational-level performance aspirations trigger middle managers' divergent strategic behavior. We built theory on the strategic renewal process by highlighting its behavioral underpinnings among middle managers. We also furthered performance aspirations research by showing that whether individual- or organizational-level feedback is heeded by managers hinges greatly on their degree of organizational identification.

\section{ACKNOWLEDGEMENTS}

We thank our editor Alfonso Gambardella and the two anonymous reviewers for their insightful and developmental suggestions. We also thank Luca Berhicci, Danieala Blettner, Garry Bruton, Lindy Greer, Maddy Janssens, Franz Kellermanns, Bernardo Lima, and Jorge Walter for their invaluable feedback to earlier versions of this article.

\section{ORCID}

Murat Tarakci (D) http://orcid.org/0000-0003-1936-6267

\section{REFERENCES}

Ahearne, M., Lam, S. K., \& Kraus, F. (2013). Performance impact of middle managers' adaptive strategy implementation: The role of social capital. Strategic Management Journal, 35(1), 68-87.

Aguinis, H. (1995). Statistical power with moderated multiple regression in management research. Journal of Management, 21(6), $1141-1158$.

Ashford, S. J., \& Barton, M. A. (2007). Identity-based issue selling. In C. A. Bartel, S. Blader, \& A. Wrzesniewski (Eds.), Identity and teh modern organization (pp. 223-244). Mahwah, NJ: Lawrence Erlbaum.

Ashforth, B. E., Harrison, S. H., \& Corley, K. G. (2008). Identification in organizations: An examination of four fundamental questions. Journal of Management, 34(3), 325-374.

Ashforth, B. E., \& Mael, F. (1989). Social identity theory and the organization. Academy of Management Review, 14(1), 20-39.

Audia, P. G., \& Brion, S. (2007). Reluctant to change: Self-enhancing responses to diverging performance measures. Organizational Behavior and Human Decision Processes, 102(2), 255-269.

Bandura, A. (1997). Self-efficacy: The exercise of control. New York, NY: Freeman.

Baum, J. A., \& Dahlin, K. B. (2007). Aspiration performance and railroads' patterns of learning from train wrecks and crashes. Organization Science, 18(3), 368-385.

Baum, J. A. C., Rowley, T. J., Shipilov, A. V., \& Chuang, Y. T. (2005). Dancing with strangers: Aspiration performance and the search for underwriting syndicate partners. Administrative Science Quarterly, 50(4), 536.

Bertrand, M., \& Mullainathan, S. (2003). Enjoying the quiet life? Corporate governance and managerial preferences. Journal of Political Economy, 111(5), 1043-1075.

Brewer, M. B. (1991). The social self: On being the same and different at the same time. Personality and Social Psychology Bulletin, 17(5), 475-482.

Bromiley, P., \& Harris, J. D. (2014). A comparison of alternative measures of organizational aspirations. Strategic Management Journal, 35(3), 338-357.

Bromiley, P., Miller, K. D., \& Rau, D. (2001). Risk in strategic management research. In M. A. Hitt, R. E. Freeman, \& J. S. Harrison (Eds.), The blackwell handbook of strategic management (pp. 259-288). Malden, MA: Blackwell.

Burgelman, R. A. (1991). Intraorganizational ecology of strategy making and organizational adaptation: Theory and field research. Organization Science, 2(3), 239-262.

Burgelman, R. A. (1994). Fading memories: A process theory of strategic business exit in dynamic environments. Administrative Science Quarterly, 39(1), 24-56.

Cyert, R. M., \& March, J. G. (1963). A behavioral theory of the firm. Englewood Cliffs, NJ: Prentice-Hall.

Dutton, J. E., \& Ashford, S. J. (1993). Selling issues to top management. Academy of Management Review, 18(3), $397-428$.

Dutton, J. E., Dukerich, J. M., \& Harquail, C. V. (1994). Organizational images and member identification. Administrative Science Quarterly, 39(2), 239-263.

Floyd, S. W., \& Lane, P. J. (2000). Strategizing throughout the organization: Managing role conflict in strategic renewal. Academy of Management Review, 25(1), 154-177. 
Floyd, S. W., \& Wooldridge, B. (1992). Middle management involvement in strategy and its association with strategic type: A research note. Strategic Management Journal, 13(1), 153-167.

Floyd, S. W., \& Wooldridge, B. (1997). Middle management's strategic influence and organizational performance. Journal of Management Studies, 34(3), 465-485.

Gaba, V., \& Joseph, J. (2013). Corporate structure and performance feedback: Aspirations and adaptation in M-form firms. Organization Science, 24(4), 1102-1119.

Gavetti, G., Levinthal, D., \& Ocasio, W. (2007). Neo-carnegie: The Carnegie School's past, present, and reconstructing for the future. Organization Science, 18(3), 523-536.

Gelman, A., \& Hill, J. (2006). Data analysis using regression and multilevel/hierarchical models. New York: Cambridge University Press.

Glynn, M. A. (2000). When cymbals become symbols: Conflict over organizational identity within a symphony orchestra. Organization Science, 11(3), 285-298.

Greve, H. R. (1998). Performance, aspirations, and risky organizational change. Administrative Science Quarterly, 43(1), 58-86.

Greve, H. R. (2003a). A behavioral theory of R\&D expenditures and innovations: Evidence from shipbuilding. Academy of Management Journal, 46(6), 685-702.

Greve, H. R. (2003b). Organizational learning from performance feedback: A behavioral perspective on innovation and change. Cambridge, U.K: Cambridge University Press.

Greve, H. R. (2008). A behavioral theory of firm growth: Sequential attention to size and performance goals. Academy of Management Journal, 51(3), 476-494.

Harris, J., \& Bromiley, P. (2007). Incentives to cheat: The influence of executive compensation and firm performance on financial misrepresentation. Organization Science, 18(3), 350-367.

Haslam, S. (2001). Psychology in organisations: The social identity approach. London, England: SAGE.

Heritage Foundation. (2017). Index of economic freedom. Retrieved from http://www.heritage.org/index

Henisz, W. J. (2000). The institutional environment for economic growth. Economics \& Politics, 12(1), 1-31.

Hill, C. W., Hitt, M. A., \& Hoskisson, R. E. (1992). Cooperative versus competitive structures in related and unrelated diversified firms. Organization Science, 3(4), 501-521.

Hofstede, G., Hofstede, G. J., \& Minkov, M. (2010). Cultures and organizations: Software of the mind. Revised and Expanded. New York, NY: McGraw-Hill.

Hogg, M. A., \& Terry, D. I. (2000). Social identity and self-categorization processes in organizational contexts. Academy of Management Review, 25(1), 121-140.

Hornsby, J. S., Kuratko, D. F., \& Zahra, S. A. (2002). Middle managers' perception of the internal environment for corporate entrepreneurship: Assessing a measurement scale. Journal of Business Venturing, 17(3), 253-273.

Hoskisson, R. E., \& Hitt, M. A. (1988). Strategic control systems and relative R\&D investment in large multiproduct firms. Strategic Management Journal, 9(6), 605-621.

Huy, Q. N. (1999). Emotional capability, emotional intelligence, and radical change. Academy of Management Review, 24(2), 325-345.

Huy, Q. N. (2002). Emotional balancing of organizational continuity and radical change: The contribution of middle managers. Administrative Science Quarterly, 47(1), 31-69.

Jansen, J. J. P., Van Den Bosch, F. A. J., \& Volberda, H. W. (2006). Exploratory innovation, exploitative innovation, and performance: Effects of organizational antecedents and environmental moderators. Management Science, 52(11), 1661-1674.

Jordan, A. H., \& Audia, P. G. (2012). Self-enhancement and learning from performance feedback. Academy of Management Review, $37(2), 211-231$.

Kacmar, K. M., \& Ferris, G. R. (1991). Perceptions of organizational politics scale (POPS): Development and construct validation. Educational and Psychological Measurement, 51(1), 193-205.

Kacperczyk, A., Beckman, C., \& Moliterno, T. (2015). Internal social comparisons, risk-taking, and change: Evidence from the mutual fund industry. Administrative Science Quarterly, 60(2), 228-262.

Kluger, A. N., \& DeNisi, A. (1996). The effects of feedback interventions on performance: A historical review, a meta-analysis, and a preliminary feedback intervention theory. Psychological Bulletin, 119(2), 254-284.

Kreutzer, M., Walter, J., \& Cardinal, L. B. (2015). Organizational control as antidote to politics In the pursuit of strategic initiatives. Strategic Management Journal, 36(9), 1317-1337.

Krueger, N., \& Dickson, P. R. (1994). How believing in ourselves increases risk taking: Perceived self-efficacy and opportunity recognition. Decision Sciences, 25(3), 385-400.

Kuusela, P., Keil, T., \& Maula, M. (2017). Driven by aspirations, but in what direction? Performance shortfalls, slack resources and resource-consuming vs. resource-freeing organizational change. Strategic Management Journal, 38(5), 1101-1120.

Mael, F., \& Ashforth, B. E. (1992). Alumni and their alma mater: A partial test of the reformulated model of organizational identification. Journal of Organizational Behavior, 13(2), 103-123.

Malmendier, U., \& Taylor, T. (2015). On the verges of overconfidence. Journal of Economic Perspectives, 29(4), 3-8.

Mantere, S., \& Vaara, E. (2008). On the Problem of participation in strategy: A critical discursive perspective. Organization Science, 19(2), 341.

Marginson, D. E. W. (2002). Management control systems and their effects on strategy formation at middle-management levels: evidence from a UK organization. Strategic Management Journal, 23(11), 1019-1031. 
Maxwell, S. E., \& Delaney, H. D. (1993). Bivariate median splits and spurious statistical significance. Psychological Bulletin, 113(1), $181-190$.

Mom, T. J. M., Van Den Bosch, F. A. J., \& Volberda, H. W. (2009). Understanding variation in managers' ambidexterity: Investigating direct and interaction effects of formal structural and personal coordination mechanisms. Organization Science, 20, 812-828.

Nonaka, I. (1994). A dynamic theory of organizational knowledge creation. Organization Science, 5(1), 14-37.

O’Brien, J. P., \& David, P. (2014). Reciprocity and R\&D search: Applying the behavioral theory of the firm to a communitarian context. Strategic Management Journal, 35(4), 550-565.

Obloj, T., \& Zenger, T. (2017). Organization design, proximity, and productivity responses to upward social comparison. Organization Science, 28(1), 1-18.

Ocasio, W. (1997). Towards an attention-based view of the firm. Strategic Management Journal, 18, 187-206.

Ocasio, W. (2011). Attention to attention. Organization Science, 22(5), 1286-1296.

Pappas, J. M., \& Wooldridge, B. (2007). Middle managers' divergent strategic activity: An investigation of multiple measures of network centrality. Journal of Management Studies, 44(3), 323-341.

Park, K. M. (2007). Antecedents of convergence and divergence in strategic positioning: The effects of performance and aspiration on the direction of strategic change. Organization Science, 18(3), 386-402.

Riketta, M. (2005). Organizational identification: A meta-analysis. Journal of Vocational Behavior, 66(2), 358-384.

Rogan, M., \& Mors, M. L. (2014). A network perspective on individual-level ambidexterity in organizations. Organization Science, 25(6), 1860-1877.

Sanders, W. G., \& Hambrick, D. C. (2007). Swinging for the fences: The effects of CEO stock options on company risk taking and performance. Academy of Management Journal, 50(5), 1055-1078.

Shinkle, G. A. (2012). Organizational aspirations, reference points, and goals building on the past and aiming for the future. Journal of Management, 38(1), 415-455.

Sitkin, S. B., \& Pablo, A. L. (1992). Reconceptualizing the determinants of risk behavior. Academy of Management Review, 17(1), 9-38.

Snijder, T. A. B., \& Bosker, R. J. (1994). Modeled variance in two-level models. Sociological Methods and Research, 22, $342-363$.

Tang, Y., Li, J., \& Yang, H. (2015). What i see, what I do: How executive hubris affects firm innovation. Journal of Management, 41(6), 1698-1723.

Tarakci, M., Greer, L. L., \& Groenen, P. J. F. (2016). When does power disparity help or hurt group performance? Journal of Applied Psychology, 101(3), 415-429.

Tolli, A. P., \& Schmidt, A. M. (2008). The role of feedback, causal attributions, and self-efficacy in goal revision. Journal of Applied Psychology, 93(3), 692-701.

Voss, Z. G., Cable, D. M., \& Voss, G. B. (2006). Organizational identity and firm performance: What happens when leaders disagree about "who we are?". Organization Science, 17(6), 741-755.

Vuori, T. O., \& Huy, Q. N. (2016). Distributed attention and shared emotions in the innovation process how nokia lost the smartphone battle. Administrative Science Quarterly, 61(1), 9-51.

Washburn, M., \& Bromiley, P. (2012). Comparing aspiration models: The role of selective attention. Journal of Management Studies, 49(5), 896-917.

Wiseman, R. M., \& Gomez-Mejia, L. R. (1998). A behavioral agency model of managerial risk taking. Academy of Management Review, 23(1), 133-153.

Wooldridge, B., \& Floyd, S. W. (1990). The strategy process, middle management involvement, and organizational performance. Strategic Management Journal, 11(3), 231-241.

Wooldridge, B., Schmid, T., \& Floyd, S. W. (2008). The middle management perspective on strategy process: Contributions, synthesis, and future research. Journal of Management, 34(6), 1190-1221.

\section{SUPPORTING INFORMATION}

Additional Supporting Information may be found online in the supporting information tab for this article.

How to cite this article: Tarakci M, Ateş NY, Floyd SW, Ahn Y, Wooldridge B. Performance feedback and middle managers' divergent strategic behavior: The roles of social comparisons and organizational identification. Strat Mgmt J. 2018;39:1139-1162. https://doi.org/ $\underline{10.1002 / \mathrm{smj} .2745}$ 